\title{
A STUDY ABOUT FACTORS INFLUENCING THE DECISION-MAKING PROCESS ON MATERIALS MANAGEMENT AND INVENTORY CONTROL TECHNIQUES
}

\author{
M.Ponnrajakumari, M.Saravanan \\ Department of ECE \\ Velammal Engineering College, Chennai, Tamilnadu
}

\begin{abstract}
Material management is the process to provide right material at right place at right time in right quality. Company has problems in procurement and handling of raw materials and also finished products. Our analysis makes a contribution to the management of inventory in the company. It helps to improve inventories. The purpose of this study is to carry out research to analyse factors involved in inventory control decision process and its implementation for company's growth. The research is to be carried out through secondary data available in the perspective of the topic. The research focused on the concepts of inventory control decision-making process, and detailed reports of different businesses implications of inventory control decision making process and its influence in company's growth and survivals in competitive environment
\end{abstract}

Keywords- Materials Management, Inventory, Decision Making

\section{INTRODUCTION}

Every inventory represents one of the biggest numbers in a company's balance sheet, the effective inventory and control is a critical function to help indemnify the persistent and continued success of operational, distribution and manufacturing of modern business. However, the effectiveness of inventory management and control is generally measured by how well a company is able to reduce its investment in inventory, achieve maximum throughput and meeting its customer service goals while containing its operational costs. On paper, however, the concept of inventory management appears to be relatively simple, it can be defined as a process that determines what inventory items needs to be stocked, how much of the stock needs to be held on hand and when should it be reordered and at what levels. On the contrary, it is very complex in practice and its implementation within companies. The factors that cause this complexity fall into two broad classifications. Firstly, there are conflict objectives across several distinct segments within a single company and the second factor lies in the uncertainty in the nature of its supply and demand. In light of this subject and baring these concepts in mind, the aim of this paper is to critically analyze the factors involved in inventory control decision-making process and its implementation within companies.

\section{LITERATURE REVIEW}

Material Manager should maintain reports such as material to order between two dates, material assignments, waste control, when to purchase construction material, when material must be on site, and purchase order between two dates. They had mention that the efficient procurement of material represents a key role in the successful completion of the work. Poor planning and control of material, lack of material when needed, poor identification of material, remanding and inadequate storage cause losses in labor productivity and overall delays that can indirectly increase total project cost.[1] Ashwini R. Patil (2013)

Moving away from a sheer tactical role, it has earned strategic value, and organizations have become conscious of the many benefits that effective material management practices can drive, including reduced costs, higher productivity, warranted quality, increased reliability, and added the development that is going in the material management on fast track construction. Material wastage in construction projects resulted into huge financial setbacks to builders and contractors. In addition to this, it may also cause significant effects over aesthetics, health, and the general environment. These wastes needs to be managed as well as their impacts needs to be ascertained to pave way for their proper management, however in many cities of India wastes materials management is still a problem. 


\section{International Journal of Engineering Applied Sciences and Technology, 2019 \\ Vol. 4, Issue 1, ISSN No. 2455-2143, Pages 45-48 \\ Published Online May 2019 in IJEAST (http://www.ijeast.com)}

\section{INVENTORY MANAGEMENT AND CONTROL TECHNIQUE}

The following techniques are used in Inventory management and control

1 ABC Analysis

2. VED Classification

3. SDE Classification

4. High, Medium and Low Classification.

5. FSN Classification

6. SOS Analysis

7. XYZ Analysis

8. GOLF Analysis

9. Economic Order Quantity

10. Minimum-Maximum Technique

11. Two-bin Technique

The ABC inventory control technique is based on the principle that a small portion of the items may typically represent the bulk of money value of the total inventory in construction process, while a relatively large number of items may from a small part of the money value of stores

- "A" items money value is highest $70 \%$, represent only $10 \%$ of items.

- "B" items money value is medium $20 \%$, represent about $20 \%$ of items.

- "C" items money value is lowest $10 \%$, represent about $70 \%$ of items.

\section{SAFETY STOCK}

A company holds safety stock to mitigate the risk of running out of stock due to an unexpected increase in demand rate and/or lead time. In other words, it is an extra quantity of stock that can be used as a buffer to cover a higher demand rate until the next order arrives or if the delivery date shifts forward. The disadvantage of holding safety stock is an increase in carrying cost that can greatly affect business profit, and if the amount of safety stock is insufficient, a loss in sales could occur. Thus, the amount of safety stock is always a trade-off between the risk of running out and carrying cost.

Formula : There are several ways to calculate safety stock level. If the rate of demand or lead time is constant, a quite simple approach can be used.

If the lead time is constant but the demand rate is variable, the following formula can be used:

Safety Stock $=($ Daily Maximum Usage - Daily Average Usage) $\times$ Lead Time

\section{JUST IN TIME}

The just-in-time (JIT) inventory system is a management strategy that aligns raw material orders from suppliers directly with production schedules. Companies use this inventory strategy to increase efficiency and decrease waste by receiving goods only as they need them for the production process, which reduces inventory costs. This method requires producers to forecast demand accurately.

\section{ECONOMIC ORDER QUANTITIES (EOQ)}

This is basically a formula that works for minimizing the total cost of inventory management overall, hence the title 'economic order quantity'. When a company wants to use the EOQ method to minimize the overall cost of inventory management, it uses the EOQ model which is: Total inventory costs $=$ Ordering costs + Holding costs the first derivative of the function is taken to find out the equation for minimum cost:

EOQ $=$ SQRT $(2 \times$ Quantity $\times$ Cost per Order $/$ Carrying Cost per Order)

\section{Example}

ABCD Ltd. Sells Cricket balls. Per order cost is \$500 and carrying cost per unit is $\$ 20$ annually. 10,000 units per year is the demand that the company has to cater to. Calculate the order size, total orders required during a year, total carrying cost and total ordering cost for the year.

Solution

$\mathrm{EOQ}=\mathrm{SQRT}(2 \times 10,000 \times 500 / 20)=707$ units

As the demand is 20000 unites per annum, $=10,000 / 707$

Total orders $=14$.

Total ordering cost $=\$ 70,000$

Average inventory being held by the company is $\$ 353((0+707) / 2)$

The total cost of carrying is $\$ 3530$ (i.e. $632.5 \times \$ 10$ )

\section{LEAD TIME}

Lead time is the amount of time that passes from the start of a process until its conclusion. Companies review lead time in manufacturing, supply chain management, and project management during pre-processing, processing, and postprocessing stages. By comparing results against established benchmarks, they can determine where inefficiencies exist.

\section{INVENTORY DECISION MAKING}

Every business in the manufacturing industry and most businesses in the service industry require carrying out inventory. When inventory is a significant element of company, good management for it becomes necessary. Management as everyone knows, requires decisions to be made and if poor decision making is involved, the company can face losses, hence it must be done in a very organized and planned way. Poor inventory management can cause sales to fall because of frequent stock outs i.e. when the company will keep running out of stocks, it won't be able to supply according to the demand and so their sales will fall . Similarly, the company might face insufficient production for some time due to certain circumstances. It implies that even though the company would be able to produce on full capacity, it won't 


\section{International Journal of Engineering Applied Sciences and Technology, 2019 \\ Vol. 4, Issue 1, ISSN No. 2455-2143, Pages 45-48 \\ Published Online May 2019 in IJEAST (http://www.ijeast.com)}

because of its insufficient stock levels, poor decision making, poor inventory management etc. Moreover, operating expenses will increase due as there will be unnecessary carrying costs incurred because of discarding obsolete inventory. Additionally, the per unit cost of finished goods increases because of poor management as there is a lot of wastage in every process and so the cost increases overall effecting the per unit cost as well. Factors Involved in Decision Making of Inventory Management involves keeping in focus a number of elements when in the process of decision making. It is a difficult task to decide the best quantity for inventory which does not adversely affect the cash flow or show larger amount of total assets and keeps the liquid assets low.

\section{i. Order Size}

This defines the units of products per order whether one order itself means a large quantity or whether only receiving a lot of orders means a large quantity is required to be produced. Another thing to be considered is that how frequently these orders come in.

\section{ii.Number of Orders}

This tells about how many orders have been received at a given point in time.

\section{iii.Material Requirements Planning (MRP)}

Materials requirements planning (MRP) system is a softwarebased solution that works backwards from customer orders to determine when materials will be needed for production and then initiates their purchase to have delivery coincide with upcoming manufacturing runs and scheduled product delivery dates. It plans production, schedules raw material purchase and delivery, and manages completed inventory levels.

\section{iv.Suppliers of Raw Material}

A company relies heavily on the suppliers of its raw materials. If they make the delivery late, the entire company can be affected and the estimated sales can fall drastically because of late delivery of inventory or failure. It is utmost important for a company to have some very reliable suppliers and well planned system to avoid any lapses during the order processing period.

\section{v. Freight}

The cost of inventory per unit might not be too high but its freight charges can make the overall package a little too pricey. The inventory management shouldn't just focus on the price of the inventory, but also its transportation as that can also cause for a large portion of the inventory expense. This is one of the reasons why companies usually set up their production units near the raw material productions and suppliers to cut down the overall cost of inventory and hence the total cost.

\section{vi.Production Budget}

Good production budget can be made when the sales forecast is spot on. If the sales forecast isn't too dependable or valid, it won't be possible for the management to decide on the production process and hence the decision of production budget would also not be very accurate and might have a lot of loopholes one has to know the demand to forecast the sales and then decide upon the stock levels, safety stock requirements, and most importantly the overall production budget. This element also plays a vital role as it determines what plant capacity is needed. The production budget at a certain point in time if exceeds the plant capacity during that time, then the capacity of the plant has to be increased.

\section{vii. Purchasing Cost}

This aspect is somewhat covered in the production budget. The inventory management must try their best to get inventory at the best rates possible to keep the cost as low as possible. This in turn would make the profit margin bigger. The company can also lower down the prices of their products because of their low costs which in turn will attract more customers. Purchasing cost is basically the cost of placing order which consists of; purchase requisition preparing cost, purchase order preparing cost, cost of order delivery which includes postage, telephone calls, filing, etc., cost of inspection, receiving and storing i.e. cost of receiving purchased materials and voucher costs and accounting costs.

\section{VIII.CONCLUSION}

The aim of this paper was to critically analyze the factors involved in inventory control decision-making process and its implementation within companies. On the basis of the literature reviewed and analyzed it is safe to conclude that even though the right-sizing and effective management and control of inventory is a complex and challenging task, but due to the increasing pressure being placed by the top management to minimize costs and increase customer satisfaction, inventory managers are swiftly moving towards the adoption and implementation of advanced and sophisticated inventory management systems that allow them to mitigate the factors involved in the inventory control decision making processes that contribute towards high inventory costs.

The aim of this paper is to critically analyze the factors that are involved in inventory control decision-making process and its implementation within companies.

\section{REFERENCES}

[1]. Ashwini R. Patil Smita V. Pataska., (2013), Analyzing Material Management Techniques on Construction Project International Journal of Engineering and Innovative Technology Volume 3, Issue 4.

[2]. Aditya Pande, Material Management For Construction Site -A Review, Civil Engg.Dept. P.R.M.C.E.A.M Badnera. Volume 1 Issue 5.

[3]. Phani Madhavi.T (2013), Material Management In Construction - A Case Study, International Journal Of Research In Engineering And Technology.

[4]. Deodhar S. V, Construction Equipment And Job Planning, KHANN PUBLICATION,(Pg 536-538) 


\section{International Journal of Engineering Applied Sciences and Technology, 2019 \\ Vol. 4, Issue 1, ISSN No. 2455-2143, Pages 45-48 \\ Published Online May 2019 in IJEAST (http://www.ijeast.com)}

[5]. Talatu Muhammad Barwa ( 2015), Inventory Control as an Effective Decision-Making Model and Implementations for Company's Growth, International Journal of Economics, Finance and Management Sciences.

[6]. Andersson, H., Hoff, A., Christiansen, M., Hasle, G., \& Løkketangen, A. (2010), Industrial aspects and literature survey: Combined inventory management and routing. Computers \& Operations Research, (Pg 1515-1536)

[7]. Caro, F., \& Gallien, J. (2010). Inventory management of a fast-fashion retail network. Operations Research, ( Pg 257-273) [8]. Curcio, D., \& Longo, F. (2009). Inventory and internal logistics management as critical factors affecting the supply chain performances. International Journal of Simulation and Process Modelling, (Pg 278-288)

[9]. Dooley, K. J., Yan, T., Mohan, S., \& Gopalakrishnan, M. (2010). Inventory Management And The Bullwhip Effect During The 2007-2009 Recession: Evidence From The Manufacturing Sector*. Journal of supply chain management, (Pg12-18)

[10]. Gumus, A. T., \& Guneri, A. F. (2009). A multi-echelon inventory management framework for stochastic and fuzzy supply chains. Expert Systems with Applications, (Pg 55655575)

[11]. Mitra, S. (2012). Inventory management in a twoechelon closed-loop supply chain with correlated demands and returns. Computers \& Industrial Engineering, (Pg 870-879)

[12]. Schwartz, J. D., \& Rivera, D. E. (2010). A process control approach to tactical inventory management in production-inventory systems. International Journal of Production Economics, (Pg 111-124)

[13]. Stanger, S. H., Yates, N., Wilding, R., \& Cotton, S. (2012). Blood inventory management: hospital best practice. Transfusion medicine reviews, (Pg 153-163)

[14]. Zhou, S. X., \& Yu, Y. (2011). TECHNICAL NOTEOptimal Product Acquisition, Pricing, and Inventory Management for Systems with Remanufacturing. Operations Research,( Pg 514-521) 